\title{
Calibration and error investigation of large tipping bucket flow meters
}

\author{
Dimaghi Schwamback ${ }^{1}$, Jamil Alexandre Ayach Anache ${ }^{2}$, and Edson Wendland ${ }^{3}$ \\ ${ }^{1}$ Universidade de São Paulo Escola de Engenharia de São Carlos \\ ${ }^{2}$ Universidade de Sao Paulo Escola de Engenharia de Sao Carlos \\ ${ }^{3}$ University of São Paulo
}

October 13, 2020

\begin{abstract}
Inherent errors in tipping bucket flow meters may limit monitoring data reliability. In this work, we perform the static and dynamic calibration of four large tipping buckets, apply different regression curves and investigate the possible measurement error sources. The volumetric capacity (static calibration) of each piece of equipment was determined. They were tested (dynamic calibration) under ten flow intensities, ranging from low to high rainfall intensities (return period larger than 100 years). For each flow rate, the measurement was recorded during six time intervals (1, 2, 5, 10, 20 and 30 minutes) and four regression equations - linear, potential, $\mathrm{T}$ vs. $1 / \mathrm{Q}$ and quadratic - were tested. According to the static calibration, the equipment has a volumetric capacity of $11.63 \mathrm{~mL}$ (TB1), $64.16 \mathrm{~mL}$ (TB2), $139.86 \mathrm{~mL}$ (TB3) and $660.95 \mathrm{~mL}$ (TB4). When tested under different flow rates (dynamic calibration), underestimations were identified according to the size of the cavity: TB1 (3.31\%), TB2 (5.75\%), TB3 (9.33\%) and TB4 (13.57\%). Among the alternative curves, linear regression showed the best correlation (above 99\%) with the monitored data. Using this method, the measurement errors were reduced to $-1.35 \%$ (TB1), $0.04 \%$ (TB2), $3.18 \%$ (TB3) and $3.73 \%$ (TB4). We investigated how the different variables (tipping speed, cavity volumetric capacity and time interval of data collection) influenced the error. Errors follow a parabolic function of tipping velocity and a linear function of cavity volumetric capacity. The time interval of data collection interfered in the data sampled, however no statistical correlation was found. Among those variables, cavity size is the most important one. Given its low cost we aimed to minimize the inherent error in large tipping buckets flow meters and encourage its application, increasing in-situ collection of hydrological data.
\end{abstract}

\section{Calibration and error investigation of large tipping bucket flow me- ters}

Calibration and errors in tipping buckets

Dimaghi Schwamback ${ }^{1 *}$, Jamil A. A. Anache ${ }^{2}$, Edson Wendland ${ }^{1}$

${ }^{1}$ Department of Hydraulic Engineering and Sanitary, São Carlos School of Engineering (EESC), University of São Paulo (USP), CxP. 359, São Carlos, SP, 13566 590, Brazil.

${ }^{2}$ Federal University of Mato Grosso do Sul, CxP. 549, Campo Grande, MS, 79070-900, Brazil.

ORCID

Dimaghi Schwamback: 0000-0002-3139-0190 
Jamil A. A. Anache: 0000-0002-4460-2914

Edson Wendland: 0000-0003-3374-608X

\section{ACKNOWLEDGMENTS}

The authors would like to thank the São Paulo Research Support Foundation (FAPESP, processes 2015/03806-1 and 2019/24292-7) and the Brazilian National Council for Scientific and Technological Development (CNPq, grant numbers 165101/2018-0) for the financial support that made the present study possible. This study was also financed in part by the Coordination for the Improvement of Higher Education Personnel (CAPES, Finance Code 001). Finally, the authors acknowledge the Graduate Program in Hydraulic Engineering and Sanitation - PPGSHS (USP-EESC) for the scientific support.

\section{Hosted file}

Manuscript.pdf available at https://authorea.com/users/366802/articles/486442-calibrationand-error-investigation-of-large-tipping-bucket-flow-meters

(a)

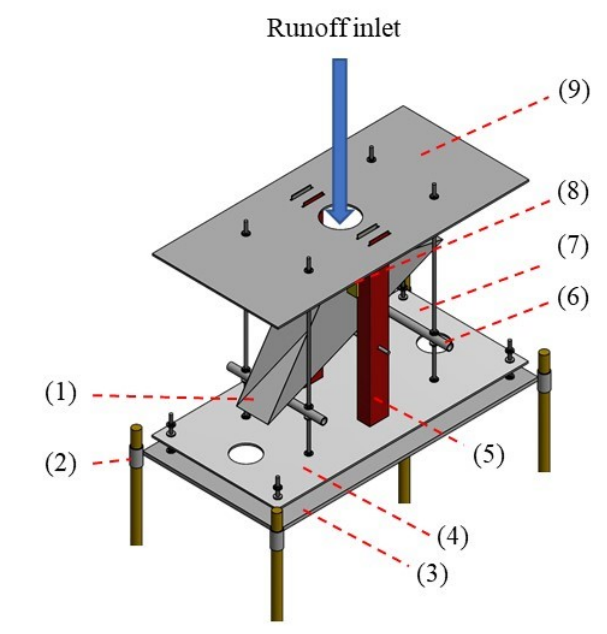

(b)
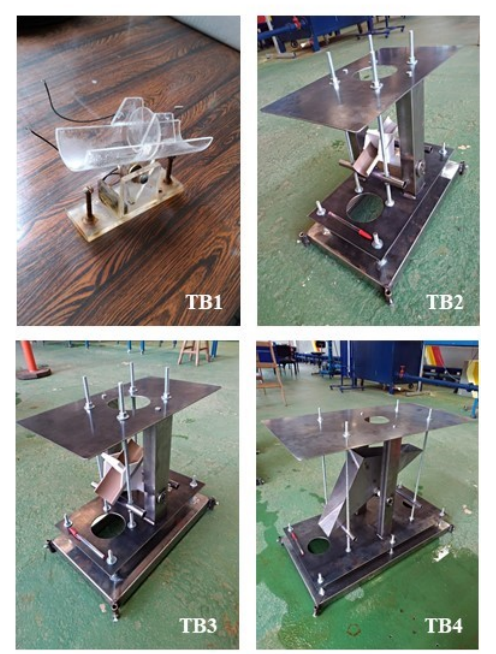

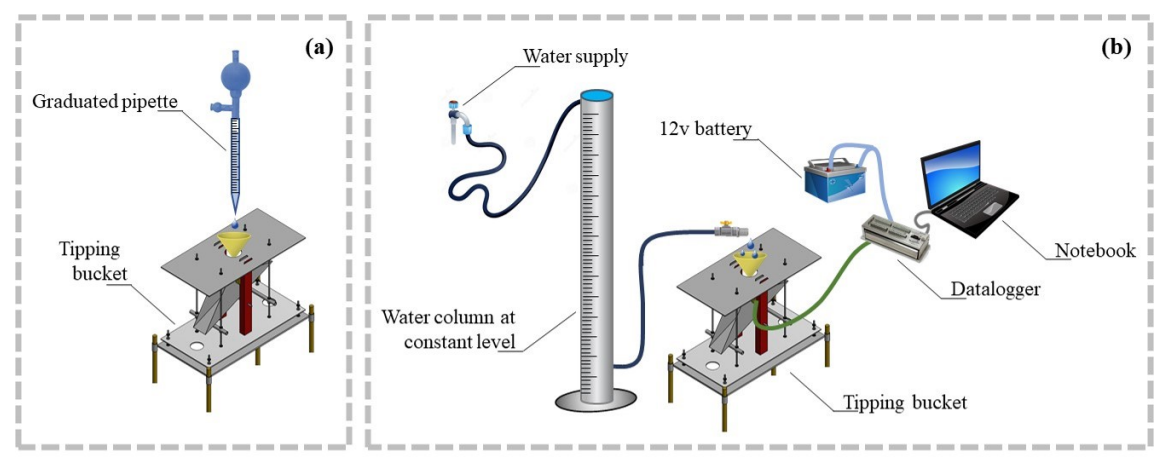



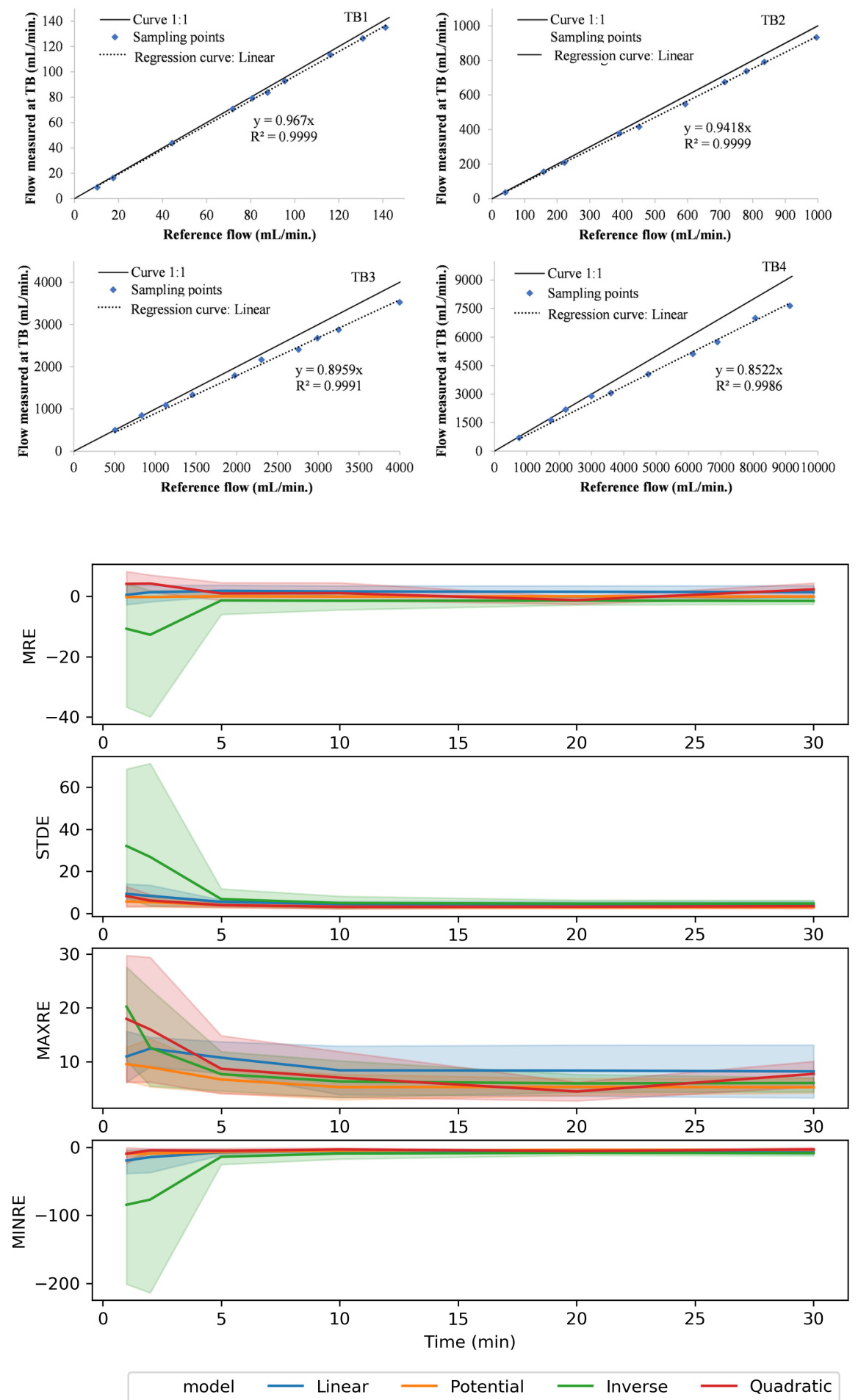

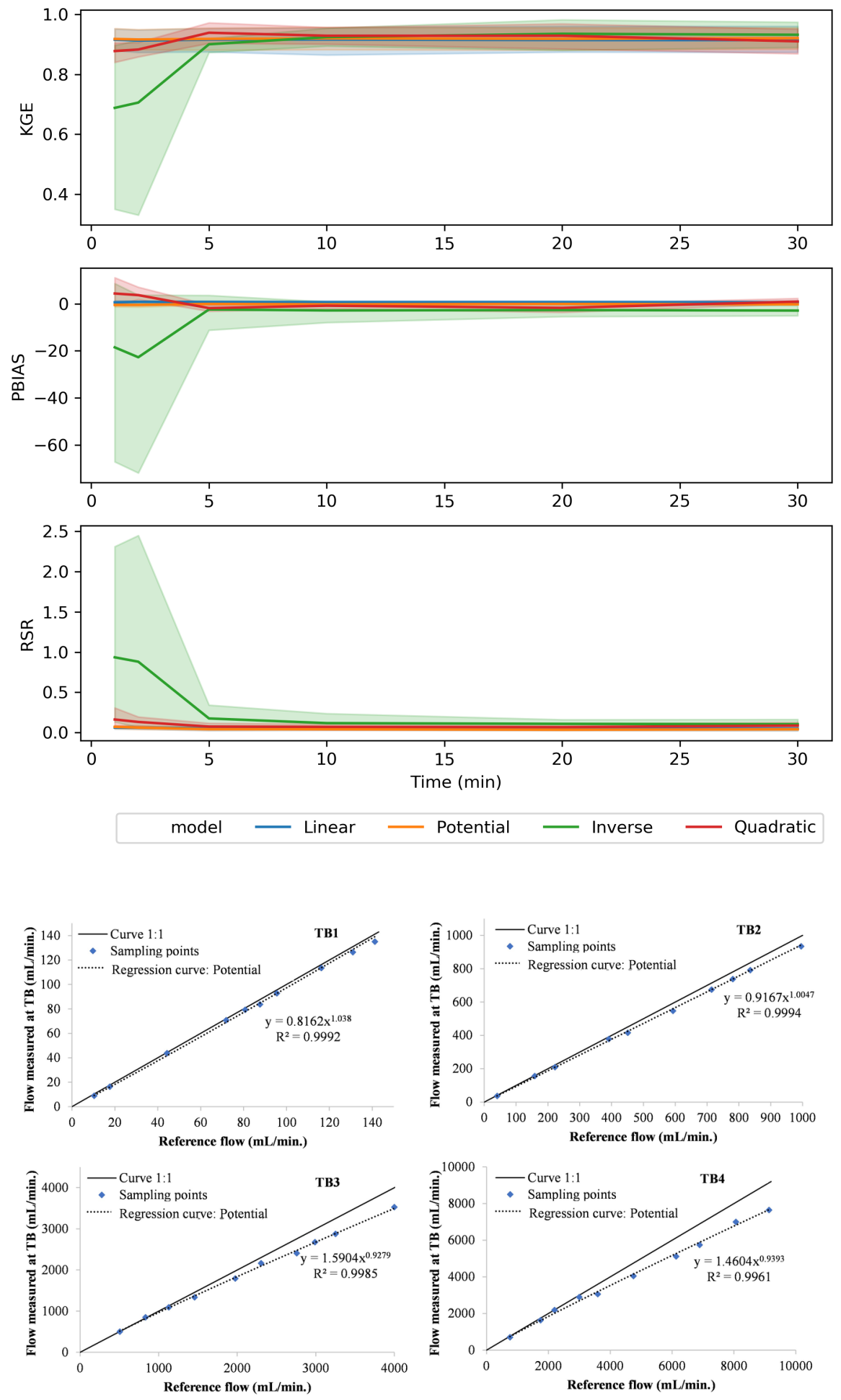

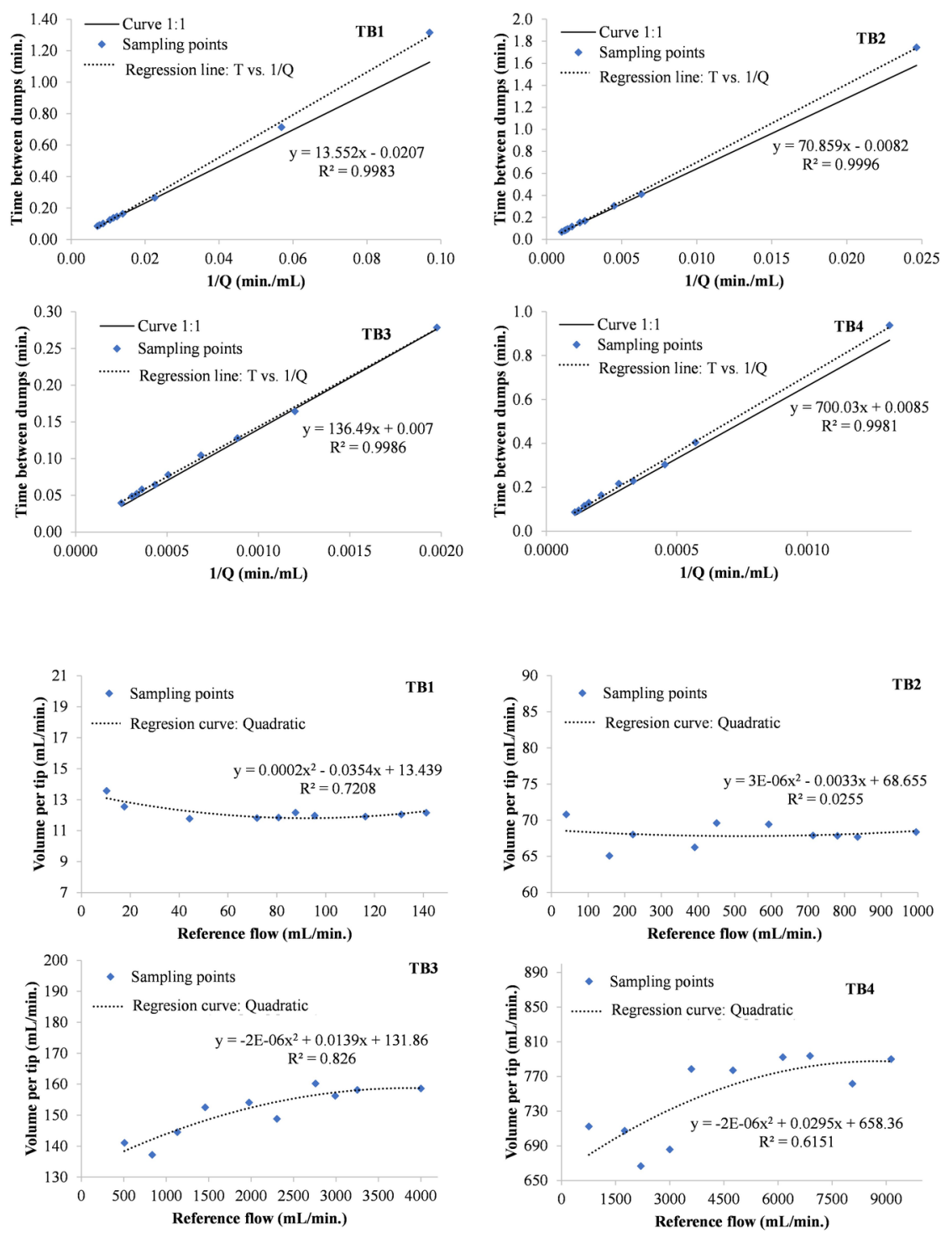


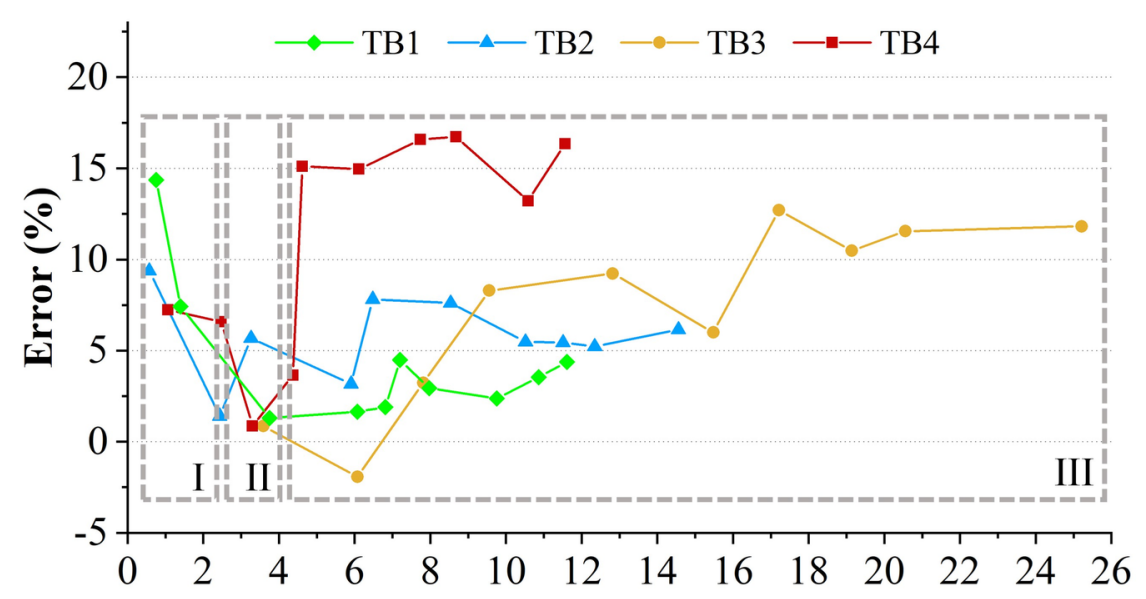

Tipping speed (unit/minute)
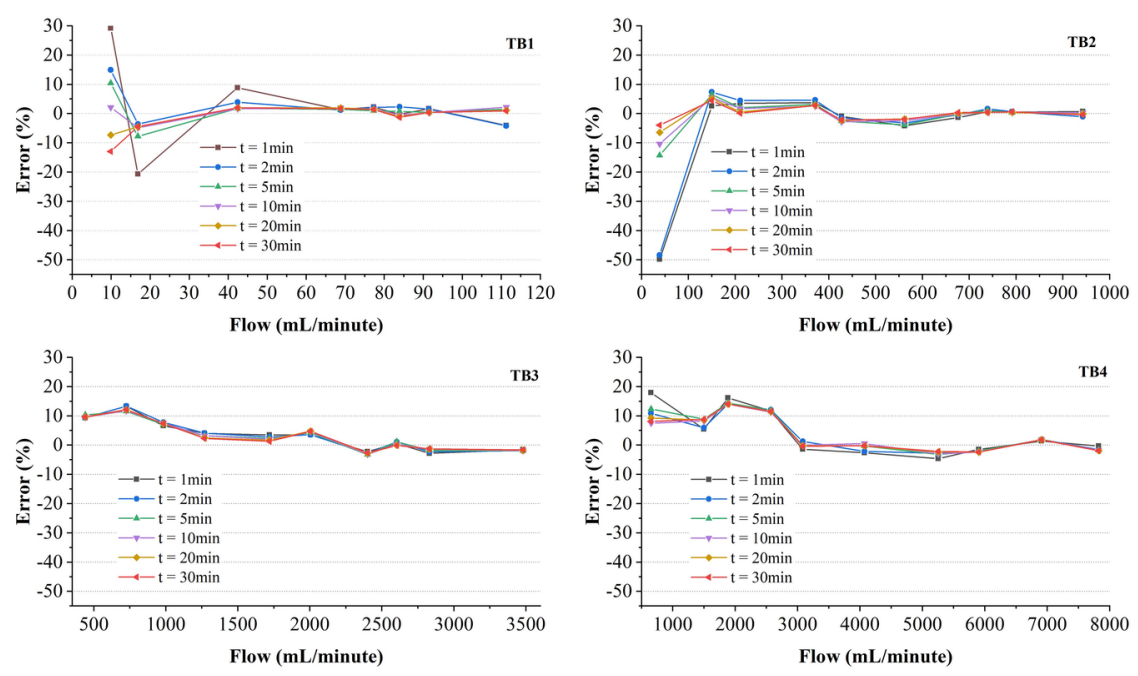

\section{Hosted file}

Table 1.pdf available at https://authorea.com/users/366802/articles/486442-calibration-anderror-investigation-of-large-tipping-bucket-flow-meters

\section{Hosted file}

Table 2.pdf available at https://authorea.com/users/366802/articles/486442-calibration-anderror-investigation-of-large-tipping-bucket-flow-meters

\section{Hosted file}

Table 3.pdf available at https://authorea.com/users/366802/articles/486442-calibration-anderror-investigation-of-large-tipping-bucket-flow-meters

\section{Hosted file}


Table 4.pdf available at https://authorea.com/users/366802/articles/486442-calibration-anderror-investigation-of-large-tipping-bucket-flow-meters 